\title{
PROPOSTA DE IMPLEMENTAÇÃO DE TREINAMENTO PARA DESENVOLVIMENTO DE COMPETÊNCIAS NO SETOR LOGÍSTICO: ESTUDO DE CASO NA EMPRESA GEMAR SUPERMERCADO
}

\section{ARTIGO ORIGINAL}

MOURA, Saulo Roberto da Silva ${ }^{1}$, ROBERTO, José Carlos Alves², OLIVEIRA, Daniel Barroso ${ }^{3}$

MOURA, Saulo Roberto da Silva. ROBERTO, José Carlos Alves. OLIVEIRA, Daniel Barroso. Proposta de implementação de treinamento para desenvolvimento de competências no setor logístico: estudo de caso na Empresa Gemar Supermercado. Revista Científica Multidisciplinar Núcleo do Conhecimento. Ano 06, Ed. 11, Vol. 03, pp. 05-28. Novembro de 2021. ISSN: 2448-0959, Link de acesso: https://www.nucleodoconhecimento.com.br/administracao/gemar-supermercado, DOI: 10.32749/nucleodoconhecimento.com.br/administracao/gemar-supermercado

\section{RESUMO}

O presente artigo teve como propósito realizar um estudo de caso na empresa Gemar Supermercado, que atua na área de serviços de comercialização varejista e de mercadorias em geral, com dominância de produtos alimentícios. Com base na pesquisa realizada através do diagnóstico organizacional, identificou-se a área da logística como a mais crítica, principalmente, no que se refere à capacitação dos colaboradores. Diante disso, levantou-se o seguinte questionamento: como as políticas de capacitações operativas podem proporcionar melhorias contínuas no processo logístico? O objetivo geral do artigo é propor a implementação de um programa de gestão por competências com práticas e técnicas a fim de aperfeiçoar o desempenho dos colaboradores nos processos logísticos do Gemar

\footnotetext{
${ }^{1}$ Graduando do curso de Administração.

${ }^{2}$ Orientador. Mestre em Engenharia de produção. Especialista Logística empresarial. Graduado em Administração com Ênfase em Marketing.

${ }^{3}$ Coorientador. Bacharel curso de Administração.
} 
Supermercado. A metodologia utilizada na pesquisa foi aplicada e qualitativa, de caráter exploratório, realizando levantamento de dados com colaboradores e gestores. Como resultados, foi proposto um conjunto de ações interventivas que permitem a estruturação de processos de reciclagem constante, visando a melhora da capacidade operativa dos colaboradores que atuam no departamento de logística. As ações foram gerenciadas, em sua introdução, pela ferramenta da qualidade $5 \mathrm{~W} 2 \mathrm{H}$. Por fim, concluímos que através das políticas de capacitação e treinamento constante dos colaboradores utilizando estratégias da gestão por competência, é possível que haja melhorias no desenvolvimento logístico do supermercado.

Palavras-chaves: logística, treinamento, gestão por competência, colaboradores.

\section{INTRODUÇÃO}

O presente artigo surgiu a partir do Diagnóstico Organizacional realizado na empresa Gemar Supermercado. Os dados obtidos destacaram o setor Logístico como a área que apresenta mais pontos fracos e pontos a melhorar, quando comparada aos demais setores analisados. Neste contexto, é necessário o entendimento da importância do setor logístico dentro da rotina empresarial, pois é por meio dele que a gestão consegue controlar os recursos, informações e equipamentos essenciais para o bom funcionamento da empresa.

Sendo assim, observaram-se problemas com a armazenagem dos produtos em estoque e no acompanhamento do giro destes, destacando a imperícia do setor logístico do supermercado. Vale ressaltar que esta falha acarreta uma série de prejuízo à empresa, devido ao acúmulo de mercadorias e produtos obsoletos.

Portanto, o objetivo deste artigo é propor a implementação de políticas de treinamento, baseando-se nas técnicas de gestão por competência a fim de estimular o desenvolvimento tanto dos colaboradores, quanto dos processos logísticos do supermercado. 
Sendo assim, o presente estudo de caso pretende responder a seguinte problemática: como as políticas de capacitações operativas podem proporcionar melhorias contínuas no processo logístico?

A metodologia deste estudo caracteriza-se, quanto à natureza aplicada, com abordagem quali-quantitativa, por meio de coleta e análise de dados obtidos através de entrevistas e pesquisas bibliográficas. Quanto aos fins, o artigo tem caráter exploratório, devido ao levantamento de dados com colaboradores e gestores, além de pesquisa bibliográfica para embasamento.

Como objetivos específicos o estudo pretende descrever a relevância da gestão por competências e criar uma política estruturada de treinamento para a organização; investigar as competências prioritárias, bem como as práticas e técnicas logísticas que precisam ser implementadas no supermercado estudado.

Como resultados, este artigo aborda um conjunto de ações interventivas que permitem à organização maximizar a eficiência das operações logísticas ancoradas na evolução da capacidade operativa dos colaboradores do departamento logístico permeados pelo treinamento contínuo e estruturado, promovendo o desenvolvimento das competências da equipe.

\section{FUNDAMENTAÇÃO TEÓRICA}

\subsection{A RELEVÂNCIA DA LOGÍSTICA AO LONGO DA HISTÓRIA}

A logística originou-se no século XVIII, no reinado de Luiz XIV. Nesta época, havia o posto de Marechal - General de Lógis - que era responsável pelo suprimento e transporte do material bélico nas batalhas. Segundo Moura (1998), a logística surgiu no Brasil entre as décadas de 1980 e 1990, devido a mudança na forma com que as organizações viam seus clientes. Até então, acreditava-se que os serviços prestados eram suficientes para atenderem às necessidades do cliente, sem se importar com a percepção destes. 
Fernandes (2012) refere-se à logística como a responsável por programar, administrar sistemas de controle de transporte, localização geográfica dos estoques, de produtos acabados e inacabados pelo menor custo. Já Procópio (2015) conceitua que a logística se encarrega do desenvolvimento de atividades como: operação, movimentação e suprimento. Além disso, também trata da distribuição de materiais, recursos, serviços e informação, assim como, dos processos de planejamentos, controle de programação de produção de bens e serviços, entre outros. Logo, a base da logística é a de administração e controle de um sistema integrado, que inclui desde o fornecedor até o consumidor final.

$\mathrm{Na}$ atualidade $\mathrm{o}$ mercado se mostra cada vez mais globalizado e, consequentemente, mais competitivo, obrigando as empresas a estarem em constante atualização para que consigam atender às expectativas dos clientes, e é por meio da logística, que os prazos se cumprem no tempo estimado e a organização obtém lucros.

Loma et al. (2018) discorrem que a logística bem planejada redireciona todos os processos dentro de uma empresa fazendo com que estes andem juntos, em sincronia. Porém, para que isso ocorra, os colaboradores precisam estar em harmonia, integrados e, sobretudo, aptos às constantes mudanças do mercado empresarial.

Contudo, pode-se afirmar que um bom gerenciamento do setor logístico proporciona vantagem competitiva à empresa. Esta, por sua vez, será capaz de exercer posições superiores aos concorrentes no que se refere à preferência dos clientes. Portanto, todo empenho fornecido pelos colaboradores dentro do processo logístico acarretará resultados positivos a empresa. 


\subsection{GERENCIAMENTO DO ESTOQUE COMO FERRAMENTA CORRETIVA DO SETOR LOGÍSTICO}

O gerenciamento de estoque é primordial na estratégia operacional de toda empresa, pois ele afeta o controle de custos, age diretamente no fluxo e agilidade de processos tanto internos como externos e, ainda, aperfeiçoa as operações e serviços disponibilizados aos clientes. Segundo Abras (2017), na falta de gerenciamento de estoques, os principais afetados serão as redes de supermercados, já que a ausência de controle e supervisão acarreta perdas expressivas aos comerciantes.

Desta forma, Gomes; Martins e Almeida (2018), afirmam que a máxima obtenção de lucro é o principal objetivo de qualquer empresa, neste contexto, prioriza-se o fluxo do capital evitando que este fique inativo. Ainda na fala dos autores, a gestão de estoque atua como uma ferramenta que auxilia o gestor a equilibrar a produção, demanda e estoque, de maneira que trabalhem em sincronia.

De acordo com Masenssine et al. (2018), o estoque passou a ser visto como fator essencial para a logística, devido às novas imposições do mercado. Em contrapartida, os clientes responsabilizam as empresas quanto a necessidade de vigilância contínua a respeito dos estoques, pois correspondem a uma atividade que estabelece níveis elevados na qualidade do processo logístico requerendo monitoramento diário, já que as falhas do setor resultam em prejuízos, como uma reação em cadeia.

Ballou (2012) garante que as empresas que buscam ser autossuficientes precisam encontrar o nível ideal de mercadorias estocadas, levando em consideração a realidade e a rotina da empresa. Com isso, faz-se necessário adaptar os espaços de armazenagem, observando a rotatividade com que os produtos são procurados e seus valores. Empresas que possuem estoques desnecessários criam incontáveis custos devido ao desperdício. 
Nogueira (2012) contextualiza que diversos fatores podem influenciar diretamente o processo produtivo e, para evitar esses problemas, é necessário à aplicação correta de um sistema de armazenagem. Além dos processos produtivos, os de distribuição de produtos também se beneficiam. Um reflexo disso se dá por meio da redução de custos para o consumidor, adicionando mais valor competitivo ao processo.

Nesse sentido, Sousa et al. (2013), descrevem o controle de estoque como o responsável em manter todos os produtos necessários para o desenvolvimento da empresa, tornando-o assim um fator indispensável, já que é impossível que uma empresa consiga trabalhar sem estoque.

Outro fator determinante, em relação ao estoque, é quem o manuseia. Atualmente, no mercado logístico, cada vez mais colaboradores buscam capacitação na área e, quando uma empresa dispõe de mão de obra qualificada, há o desenvolvimento de um aspecto competitivo já que é possível aplicar conhecimentos atuais na rotina de trabalho. Desta forma, possibilitar treinamento para os colaboradores traz bons resultados a empresa, uma vez que, através de novos métodos de treinamento e capacitações para os colaboradores, a empresa expande seus níveis e aumenta a cartela de cliente.

\subsection{A GESTÃO POR COMPETÊNCIA NA RESOLUÇÃO DAS FALHAS DO SETOR LOGÍSTICO}

O mundo globalizado passou a exigir que as empresas evoluíssem em diversos fatores e assuntos. Dessa maneira, estas entenderam que colaboradores integrados, criativos e autônomos no desenvolvimento de tarefas, reflete em benefícios e lucros.

A gestão por competência, atualmente, vem colaborando diretamente para que as empresas consigam identificar os pontos fortes e fracos e, assim, promoverem a capacitação e o desenvolvimento das competências que mais se destacam nos 
colaboradores, reformulando o ambiente empresarial e fortalecendo a competitividade diante de seus concorrentes.

De acordo com Rabaglio (2013), as competências são a junção de ferramentas e práticas, objetivas e mensuráveis, que trabalham auxiliando a gestão e desenvolvimento das pessoas. Seu foco está ligado à clareza e critérios que são capazes de fazer uma identificação profunda das competências, levando em consideração as atribuições de cada cargo ou funções. Já na visão de Dutra (2013), às competências precisam ser observadas e acompanhadas.

Diante disso, conclui-se que o mundo globalizado tende a exigir mudanças dentro das empresas, espelhando de forma positiva sua imagem. Para isso, é preciso identificar o perfil ideal para a empresa, deslocando o foco da gestão do controle e integrando a gestão do desenvolvimento de forma a identificar o mérito de cada colaborador, contribuindo para o sucesso da empresa.

Os benefícios trazidos pela gestão por competências atingem não somente a empresa, mas também o colaborador. Desta forma, uma gestão que é capacitada para reconhecer seus talentos acaba desenvolvendo e inserindo cada colaborador na área onde suas competências mais se destacam.

Sendo assim, a competência não trabalha apenas na agregação de valor econômico, mas também permite agregar valor social, tanto ao colaborador quanto à empresa. Quando esse tipo de gestão atinge a solidificação dentro das empresas é possível atingir um posicionamento competitivo.

\subsection{IDENTIFICANDO AS COMPETÊNCIAS INDIVIDUAIS E ORGANIZACIONAIS}

Segundo Knapik (2012), às competências individuais precisam ser separadas das organizacionais e expõem conhecimentos, habilidades e atitudes que direcionam os grupos para a aplicação padronizada do planejamento estratégico. 
Com isso, entende-se que o desenvolvimento da competência individual funciona como meio para alcançar as metas relativas ao capital humano e intelectual, sendo assim, colaboram para a formação de um profissional apto às expectativas organizacionais.

Lima e Rocha (2012) discorrem que o desenvolvimento das competências de um indivíduo é avaliado a partir de seu desenvolvimento no espaço ocupacional, pois, ao passo que alguém se mostra mais competente, é natural que assuma atribuições mais complexas, agregando mais valor à empresa.

Entretanto, Leal et al. (2018), aborda que as competências organizacionais se relacionam com os valores individuais da empresa, ou seja, tratam de características das pessoas tidas como essenciais, as quais foram adquiridas por meio de herança genética, desenvolvidas através do conhecimento e da convivência social de cada indivíduo.

Desta forma, para que seja possível desenvolver um trabalho bem estruturado, é necessário que as empresas definam suas competências organizacionais, por meio dos indicadores como: missão, visão, valores estratégicos. Isso acarreta o fortalecimento entre gestores e $\mathrm{RH}$, preparando a empresa para execução de uma metodologia.

\subsection{TREINAMENTO}

Para que uma empresa obtenha destaque no mercado de trabalho é preciso ter em mente que seus colaboradores são uma ferramenta essencial, tendo em vista que eles são os responsáveis pela execução de tarefas, bem como 0 bom desenvolvimento delas. Vale ressaltar, também, que os colaboradores refletem a imagem da empresa frente ao mercado, contudo, investir em seus colaboradores é efetivamente positivo no alcance das metas.

Partindo deste princípio podemos certificar que investir em treinamento e capacitações para os colaboradores pode resultar muitas vezes na obtenção de

RC: 100656

Disponível em: https://www.nucleodoconhecimento.com.br/administracao/gemarsupermercado 
lucros, uma vez que um treinamento bem estruturado e executado consegue corrigir as falhas e suprir necessidades que afetam o bom funcionamento da empresa e, por consequência, sua margem de lucro.

Pereira e Passos (2014) relatam que a maioria dos treinamentos focam no processo de capacitar pessoas, instruindo os colaboradores sobre a empresa, suas políticas, regras, diretrizes, missão e visão organizacional.

Para Carlos (2012) o treinamento profissional tem a ver com preparação do colaborador e com o entendimento a respeito de novos hábitos, conhecimento, habilidades, técnicas e práticas voltadas para a efetivação da demanda necessária para o exercício da profissão.

Teófilo et al. (2013) complementam que o treinamento corresponde à atividade que se dedica a transmitir conhecimento, sendo que, seu objetivo é alcançar a capacidade através do desenvolvendo de habilidades visando o crescimento profissional e cultural do colaborador, bem como da empresa em relação a obtenção e manutenção de mão de obra capacitada que compreenda e supere os desafios.

\subsection{TIPOS DE TREINAMENTO}

O treinamento baseia-se em algumas perguntas como: por que, quem e como treinar. Mas para isso, primeiramente, há necessidade de um mapeamento das competências necessárias a fim de desenvolver um treinamento levando em consideração as competências de cada colaborador e o que pode ser feito a partir da análise organizacional das tarefas a serem executadas, como também, da análise individual e coletiva.

Para Ceccon (2013), dentre os muitos recursos empregados no processo de desenvolvimento, o treinamento é um dos mais utilizados, seu principal objetivo é aperfeiçoar o desempenho funcional, aprimorando as relações interpessoais e aumentando a produtividade. 
Desta forma, a prática precisa levar em consideração os diferentes tipos de treinamento:

- De integração: que vai objetivar e adaptar o colaborador à empresa;

- Técnico-operacional: que busca a capacitação do colaborador para a realização de tarefas específicas;

- Gerencial: procura desenvolver a competência técnica, administrativa e comportamental;

- Comportamental: busca solucionar os problemas das inter-relações no trabalho;

É necessário, portanto, que a empresa entenda com clareza o perfil do indivíduo a ser treinado, para então criar um planejamento que seja capaz de suprir as necessidades que foram detectadas em relação à aprendizagem.

Desta forma, trazendo para o cenário em estudo, fica evidente a importância de se investir em capacitação logística, seja ela destinada a novos ou a antigos colaboradores, já que o mercado de trabalho vive em constante mudança.

\section{MATERIAIS E MÉTODOS}

Na visão dos autores Libório e Terra (2015), a metodologia corresponde à junção de regras básicas de todo o aporte de pesquisadores e pensadores, descritas de maneira exata e minuciosa, com o objetivo de conseguir resultados confiáveis e, sobretudo, imparciais.

Por outro lado, Zanella (2013), aborda que a metodologia é comumente empregada de maneira errônea e equivocada no meio acadêmico, sendo interpretada apenas como um conjunto de regras que regem um trabalho científico. Faz-se necessário esclarecer que a padronização e a uniformização não correspondem à metodologia. 
Portanto, este artigo buscou diferentes métodos que auxiliassem a identificação de soluções apropriadas tanto à capacidade da empresa, quanto aos problemas expostos no Gemar Supermercado.

\subsection{PROCEDIMENTOS METODOLÓGICOS}

Os procedimentos metodológicos correspondem à fase prática do artigo, ou seja, refere-se a diversas técnicas de aplicações que podem ser utilizadas pelo pesquisador. O método escolhido, neste caso, foi o estudo de caso, que se caracteriza por ser uma pesquisa ampla com o objetivo de oferecer base a novos estudos e pesquisas, reafirmando a autenticidade de propostas.

Este artigo foi realizado através de coleta de dados e entrevista com gestores e colaboradores do supermercado, analisando e avaliando os setores operantes, identificando seus pontos fortes e suas deficiências, a fim de elaborar um programa de treinamento que atenda e solucione os problemas detectados durante a pesquisa.

$\mathrm{Na}$ visão de Yin (2015), os estudos de caso procuram descrever e analisar a pesquisa de maneira aprofundada. A qualidade do trabalho, neste caso, dependerá da sagacidade e do empenho do pesquisador em efetivar um trabalho que corresponda às práticas recomendadas.

\subsubsection{QUANTO À NATUREZA}

A natureza da pesquisa está relacionada com a finalidade do que se pretende alcançar, relacionando-se com os benefícios que serão adquiridos por meio da pesquisa, podendo ela ser: básica ou aplicada. Neste estudo de caso, adotou-se o modelo de pesquisa aplicada, com abordagem quali-quantitativa, por meio de coleta e análise de dados obtidos através de entrevistas e pesquisas bibliográficas. 
De acordo com Nascimento (2016), a pesquisa aplicada dedica-se à geração de conhecimento e procura solucionar problemas específicos direcionando a busca da verdade para aplicação.

Já para Yin (2015), os estudos quantitativos e os qualitativos se complementam e possibilitam um melhor entendimento a respeito do fenômeno estudado.

\subsubsection{QUANTO AOS FINS}

Assim como a natureza da pesquisa subdivide-se em grupos, os fins, também, podem ser delimitados em exploratórios, descritivos e explicativos.

Segundo Casarin (2012), a pesquisa exploratória trata-se de uma pesquisa preparatória para um tema pouco explorado ou sobre um assunto já antes estudado, porém, analisado sob uma nova perspectiva, servindo de base para pesquisas posteriores.

Complementando a afirmação anterior, Zanella (2013), afirma que a pesquisa exploratória tem a finalidade de acrescentar conhecimento a respeito de fenômenos. Segundo o autor, a pesquisa com esta tipologia, demonstra ser simples, porém, consegue explorar a realidade buscando maior conhecimento, para depois, planejar uma pesquisa descritiva.

Neste sentido, este artigo tem caráter exploratório, sendo desenvolvido através do levantamento de dados com colaboradores e gestores, além de pesquisa bibliográfica.

\subsubsection{QUANTO AOS MEIOS}

Na visão de Koche (2015), a pesquisa quanto aos meios tenta explicar um problema, por meio do conhecimento disponível em teorias publicadas. Neste artigo, o estudo se deu na forma de estudo de caso, tendo sua base construída a partir de pesquisa bibliográfica, revisando a literatura disponível a respeito do assunto abordado, 
inserindo ferramentas, como a: pesquisa de campo, pesquisa documental, entrevistas e observações do autor.

Trigueiro (2014) discorre que a revisão bibliográfica se constitui na etapa inicial em um processo de pesquisa, seu objetivo é ter um conhecimento antecipado da situação em estudo. Portanto, a pesquisa bibliográfica fundamenta o artigo dando-o credibilidade e cientificidade.

\subsection{CARACTERÍSTICAS DA EMPRESA}

A empresa Gemar Supermercado foi fundada na década de 90, faz parte do Grupo Gemar Comércio de Alimentos LTDA - ME, localiza-se na Av. 31 de março № 337 Bairro Centro, Anori/Amazonas, CEP: 69.440-000. Caracteriza-se como uma empresa de pequeno porte sob o CNPJ: 11976.041/0001-34 e Inscrição Estadual n: 04.227.830-9, atuante na área de serviços de comercialização varejista e mercadorias em geral, com dominância de produtos alimentícios: minimercados, mercearias e armazéns.

O horário de funcionamento é de segunda a domingo, de 07 h 00 min da manhã às 21 h 00 min da noite. O quadro de funcionários é constituído por 19 colaboradores: 01 Diretor presidente, 01 administrativo, 01 líder de caixa, 01 líder de logística, 01 líder de operações, 04 operadores de caixas, 02 auxiliares de açougue, 02 auxiliares de limpeza, 03 repositores, 03 auxiliares de logística, todos registrados pela CLT.

O Gemar Supermercado dispõe de equipamentos e estrutura moderna oferecendo mais conforto e comodidade, proporcionando uma experiência de compra agradável para todos os clientes. Além disso, oferece diversos serviços próprios, tais como: açougue, frios, laticínios, hortifrúti, adega, loteria, amplo estacionamento e ambiente climatizado.

A extensão total do terreno é de $3.000 \mathrm{~m}^{2}$, o espaço físico do estabelecimento é de $1.400 \mathrm{~m}^{2}$, distribuídos entre área de venda "salão da loja" $1.000 \mathrm{~m}^{2}$ (setor de frios, perecíveis, setor de açougue, setor FLV - frutas, legumes e verduras, salão de 
vendas, caixa, estoque com $200 \mathrm{~m}^{2}$ ) e retaguarda $400 \mathrm{~m}^{2}$ com sala da diretoria, setor financeiro, setor comercial e sanitários. Área externa com estacionamento com capacidade para 15 carros, incluindo motocicletas.

\section{RESULTADOS E DISCUSSÕES}

A análise interna realizada na empresa Gemar Supermercado possibilitou a identificação de pontos fortes, pontos fracos e pontos a melhorar dos setores existentes na empresa. Para tal identificação, foi necessário a aplicação de um questionário desenvolvido a fim destacar os níveis avaliativos de cada setor. Os setores analisados foram: Administração, Logística, Marketing, Produção/Operações, Finanças e Recursos Humanos.

Gráfico 01: Média - Desempenho por área funcional

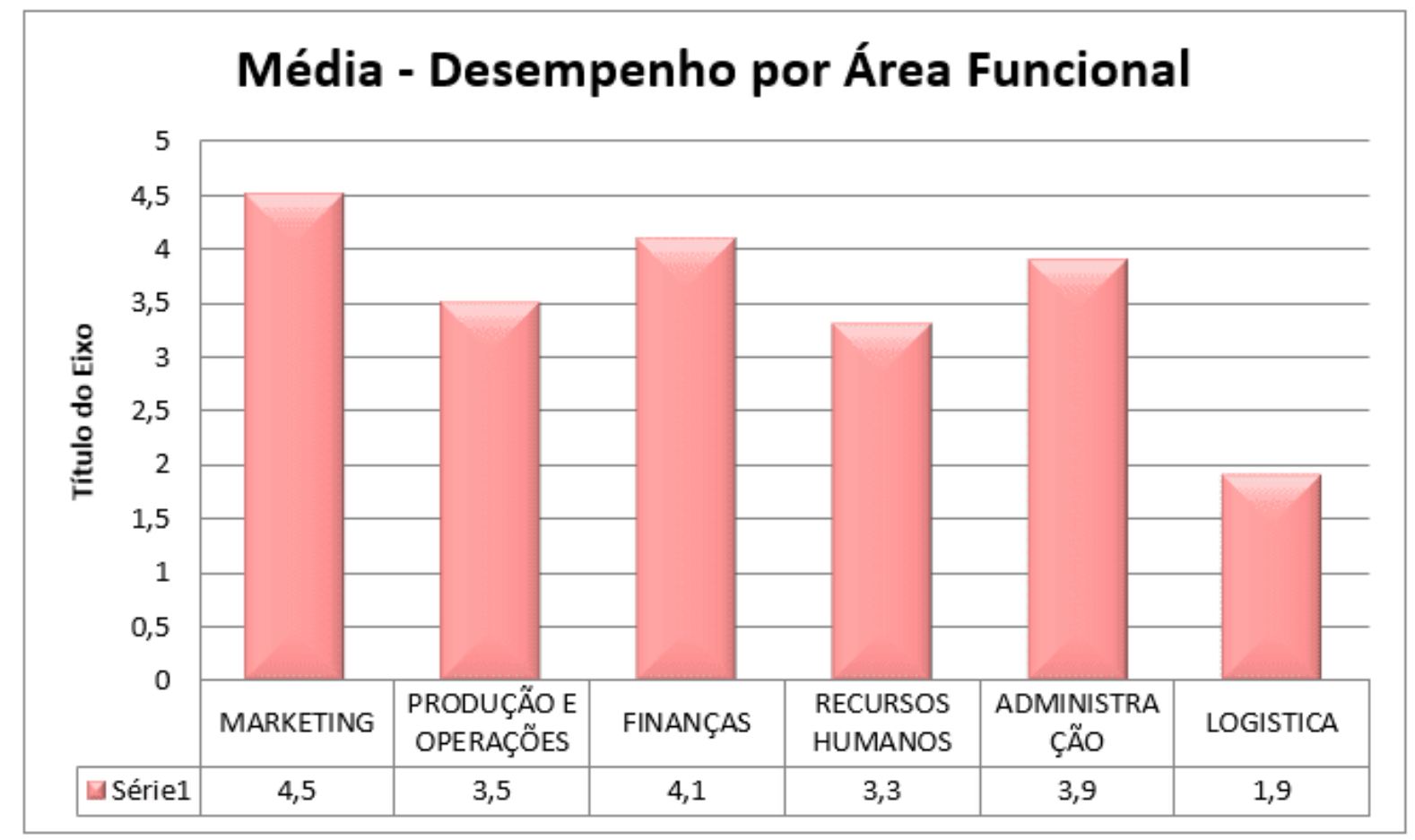

Fonte: Elaborado pelo autor com base na coleta de dados, 2021.

O gráfico 01 demonstra desde o setor mais promissor da empresa até o setor que necessita de maior empenho na correção dos erros e falhas. Seguindo esta linha de 
raciocínio, a área de Marketing destaca-se em pontos positivos, devido a utilização do marketing digital na divulgação dos produtos e promoções.

A área de Finanças e Administração estão, respectivamente, logo atrás, com os melhores desempenhos. O Supermercado tem, no momento, as finanças equilibradas, base capital estável e procura ter transparência no decorrer dos processos decisórios. Porém, uma segunda faceta retratada através da análise interna, demonstrou que as áreas críticas do supermercado vão desde o setor de Recursos Humanos, Produção e Operações até o de Logística, sendo este último, a área mais crítica.

Com base nos dados obtidos, o setor de logística destaca-se como a área que demonstra maior imperícia, em comparação com as demais áreas estudadas. Embora o setor tente desenvolver um processo de controle de estoque, os colaboradores responsáveis não possuem qualificação necessária para executar as tarefas e monitorar os diversos recursos que o sistema de processamento e controle de dados oferece. Além disso, a pouca prática e a inexistência de técnicas apropriadas para a realização eficiente de atividades, muitas vezes rotineiras, são outro problema enfrentado pelo setor logístico.

Quadro 01: Logística

ÁREA FUNCIONAL

LOGÍSTICA

1 A armazenagem dos produtos é feita de maneira correta?

2 Existe um acompanhamento do giro dos produtos?

3 Existe acompanhamento quanto reposição dos produtos nas gôndolas?

GRAU

AVALIAÇÃO

54

3

21

$\mathbf{x}$

DE

AVALIACAO

$\mathbf{x}$ 


\begin{tabular}{|c|c|c|c|c|c|c|}
\hline 4 & O espaço físico do estoque é bem-organizado? & & & & & $\mathbf{X}$ \\
\hline 5 & $\begin{array}{l}\text { A acuracidade do estoque está entre os níveis } \\
\text { aceitáveis? }\end{array}$ & & & & $\mathbf{x}$ & \\
\hline 6 & $\begin{array}{l}\text { O sistema utilizado é eficiência no planejamento e } \\
\text { controle do estoque? }\end{array}$ & & & & & $\mathbf{X}$ \\
\hline 7 & Existe um padrão no registro dos produtos? & & & & $\mathbf{x}$ & \\
\hline 8 & $\begin{array}{l}\text { Existe um alinhamento entre os setores de compra e } \\
\text { estoque? }\end{array}$ & & & & $\mathbf{x}$ & \\
\hline 9 & Os produtos perecíveis são bem armazenados? & & & $\mathbf{X}$ & & \\
\hline 10 & $\begin{array}{l}\text { Existe controle adequado em relação ao prazo de } \\
\text { validade dos produtos? }\end{array}$ & & & & & $\mathbf{X}$ \\
\hline \multicolumn{2}{|c|}{ TOTAL $(\Sigma)$} & 0 & 4 & 3 & 8 & 4 \\
\hline \multicolumn{2}{|r|}{ MÉDIA POR GRAU (POR COLUNA) } & 0 & 0,4 & 0,3 & 0,8 & 0,4 \\
\hline \multicolumn{2}{|r|}{ DESEMPENHO DA ÁREA $(\Sigma)$ TOTAL } & \multicolumn{5}{|c|}{1,9} \\
\hline
\end{tabular}

Fonte: Elaborado pelo autor com base na coleta de dados, 2021.

Um dos principais problemas encontrados é o acompanhamento no giro de produtos. Neste caso, o supermercado apresenta uma deficiência significativa, com mercadorias paradas, pouco vendidas e um estoque ineficiente com diversos produtos obsoletos, por isso, a distribuição do espaço físico carece de uma organização efetiva em seus produtos. Diante disto, a problemática é: como as políticas de capacitações operativas podem proporcionar melhorias contínuas no processo logístico?

\subsection{PLANEJAMENTO DAS AÇÕES}

Conhecido como uma das ferramentas de gestão mais utilizadas no âmbito empresarial, o planejamento das ações é uma metodologia administrativa que organiza e define metas e atividades a serem realizadas, descreve a estrutura de seu desenvolvimento, aponta os responsáveis por cada etapa e demonstra o andamento do projeto. Desta forma, é possível garantir melhores resultados. 
Quadro 02: Ações Interventivas

\begin{tabular}{|c|c|c|c|c|}
\hline Item & Ações Interventivas & Cronologia & Duração & Custo \\
\hline 1 & $\begin{array}{l}\text { Criar um mapa de competências } \\
\text { necessárias aos profissionais de } \\
\text { logística da organização. }\end{array}$ & Setembro/2021 & 30 dias & $\begin{array}{l}R \$ \\
2.500,00\end{array}$ \\
\hline 2 & $\begin{array}{l}\text { Criar um programa de priorização } \\
\text { das competências mapeadas. }\end{array}$ & Outubro/2021 & 30 dias & $\begin{array}{l}R \$ \\
3.500,00\end{array}$ \\
\hline 3 & $\begin{array}{l}\text { Identificar dentre os colaboradores } \\
\text { quais serão contemplados com o } \\
\text { programa e criar levantamento de } \\
\text { necessidades de treinamento de } \\
\text { cada colaborador. }\end{array}$ & Setembro/2021 & 5 dias & $\begin{array}{l}R \$ \\
1.500,00\end{array}$ \\
\hline 4 & $\begin{array}{l}\text { Estabelecer um cronograma } \\
\text { mensal de investimento em } \\
\text { treinamento e desenvolvimento } \\
\text { das competências. }\end{array}$ & Permanentemente & -------- & $\begin{array}{l}R \$ \\
2.500,00\end{array}$ \\
\hline \multicolumn{5}{|c|}{ Total: $\mathrm{R} \$ 10.000,00$} \\
\hline
\end{tabular}

Fonte: Elaborado pelo autor com base na coleta de dados, 2021.

As ações interventivas deste projeto buscam responder a problemática levantada por meio do diagnóstico empresarial realizado na empresa, para isto utilizou-se a ferramenta da qualidade $5 \mathrm{~W} 2 \mathrm{H}$, que por meio de perguntas diretas buscam criar um planejamento geral para a tomada de decisões necessárias à empresa.

Lisboa (2012, p. 71), afirma que "A ferramenta $5 \mathrm{~W} 2 \mathrm{H}$ funciona como base na implementação empresarial, permitindo de maneira simples que informações básicas sejam evidenciadas, e a partir daí, determinar e garantir que ações necessárias consigam ser cuidadosamente aplicadas". 
Com a introdução das ações interventivas propostas espera-se que a organização capacite os colaboradores no sentido de maximizar o resultado operacional do setor logístico por meio da eficiência operativa do departamento.

\subsection{CRIAÇÃO DO MAPA DE COMPETÊNCIAS NECESSÁRIAS AOS PROFISSIONAIS DE LOGÍSTICA DA ORGANIZAÇÃO}

O mapeamento de competências é relacionado ao ato de mapear as competências organizacionais que a empresa estudada precisa desenvolver, em outras palavras, as chamadas competências necessárias para que os objetivos estratégicos préestabelecidos consigam ser alcançados. Este mapeamento deve direcionar a empresa para o melhor caminho no gerenciamento do negócio. Diante disso, destaca-se a priorização de habilidades e particularidades tidas como fundamentais para as atividades.

Quadro 03: 5W2H - Criação do mapa de competências necessárias aos profissionais de logística da organização.

\begin{tabular}{|c|c|}
\hline \multicolumn{2}{|c|}{ DESCRIÇÃO } \\
\hline O que? & $\begin{array}{l}\text { Criar um mapa de competências necessárias aos profissionais de } \\
\text { logística da organização }\end{array}$ \\
\hline Por quê? & $\begin{array}{l}\text { Para identificar quais as reais condições do setor, e desta forma, criar } \\
\text { e definir um programa estruturado, englobando práticas e técnicas } \\
\text { capazes de retificar e prevenir falhas nos processos logísticos. }\end{array}$ \\
\hline Onde? & Setor logístico \\
\hline Quando? & 01/09/2021 à 30/09/2021 \\
\hline Quem? & Setor de RH \\
\hline Como? & $\begin{array}{l}\text { Determinando o nível de conhecimento e habilidades existentes como } \\
\text { também suas carências e necessidades. }\end{array}$ \\
\hline Quanto? & $\mathrm{R} \$ 2.500,00$ \\
\hline
\end{tabular}

Fonte: Elaborado pelo autor com base na coleta de dados, 2021. 
No quadro 2, é proposto que seja feito o mapeamento e a coleta de dados. Esperase que, com esta ação, a empresa possa entender a função que cada colaborador desenvolve, a fim de elaborar planos de capacitação e personalizar os programas de acordo com a necessidade da função.

\subsection{CRIAÇÃO DO PROGRAMA DE PRIORIZAÇÃO DAS COMPETÊNCIAS MAPEADAS}

Nesta etapa, acontece a validação e priorização das competências identificadas anteriormente. Vale ressaltar que a competência profissional pode ser definida como uma junção de conhecimentos, habilidades e atitudes, portanto, o conhecimento caracteriza-se com o saber teórico. Já a habilidade, é a aplicação do conhecimento de forma prática. Enquanto, a atitude pode ser entendida como a vontade de fazer, ou seja, é a motivação do colaborador para realizar aquilo que precisa ser feito.

Quadro 04: 5W2H - Criar um programa de priorização das competências mapeadas.

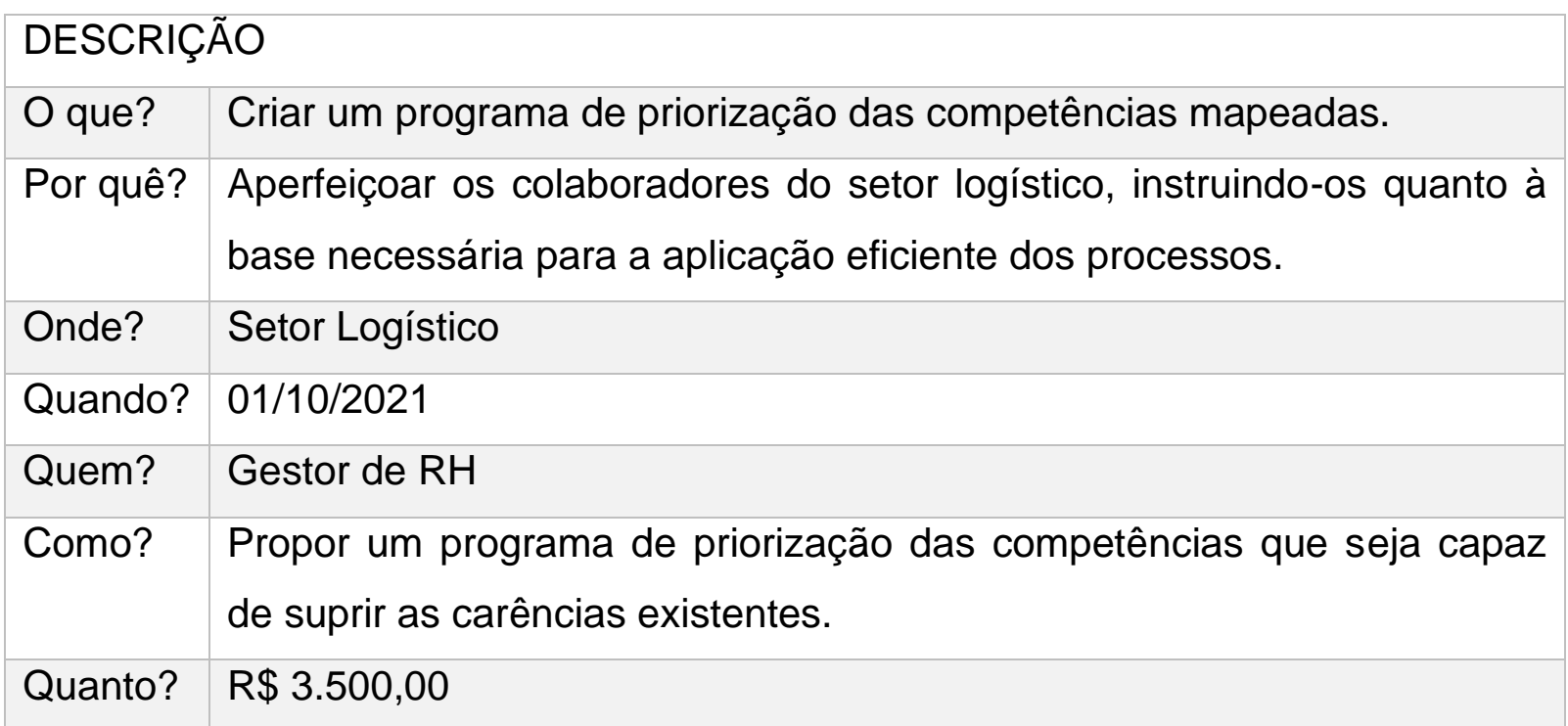

Fonte: Elaborado pelo autor com base na coleta de dados, 2021. 
No quadro 4 é proposto a criação de um programa que identifique as competências que mais contribuem com os resultados da operação da empresa, a fim de direcionar a construção dos programas de treinamento.

Espera-se com esta ação construir um mapeamento das competências a serem desenvolvidas e estabelecer os programas de treinamento necessários.

\subsection{IDENTIFICAÇÃO DOS COLABORADORES QUE SERÃO CONTEMPLADOS COM O PROGRAMA E LEVANTAMENTO DAS NECESSIDADES DE TREINAMENTO DE CADA COLABORADOR}

No momento em que as carências do treinamento e as competências empresariais dos colaboradores são estabelecidas e posicionadas, faz-se necessário agregar o atendimento a tais necessidades por meio de um programa incorporado e consistente. Neste momento, o programa entra na fase de análise e organização das ações escolhidas como prioritárias, para que possam ser implantadas em etapas de aprendizagem, seguindo o planejamento estipulado.

Dessa maneira, a organização busca integrar e adaptar o colaborador, aperfeiçoando seu desempenho em tarefas estabelecidas quanto sua área de atuação na empresa. Para isso, é realizada uma análise de maneira detalhada, através de pesquisas, entrevistas, questionários e avaliação do conhecimento, distinguindo quais os colaboradores serão contemplados com o treinamento, visando suas caraterísticas pessoais e desenvoltura diante das atividades que precisam ser executadas para a correção das falhas já pré-estabelecidas.

Quadro 05: 5W2H- Identificação dos colaboradores contemplados e criação de levantamento das necessidades de treinamento de cada colaborador.

\section{DESCRIÇÃO}

O Que? Identificar dentre os colaboradores quais serão contemplados com o programa e criar Levantamento de necessidades de treinamento de 
cada colaborador.

Por quê? A identificação das competências definirá as reais necessidades dos colaboradores, desta forma, esses aspectos serão levados em consideração resultando na criação de treinamentos específicos para cada colaborador.

Onde? Setor de Logística

Quando? 13/09/2021 à 17/09/2021

Quem? Instrutor, gestor logístico e de Rh

Como? Empregar as informações encontradas no levantamento das necessidades de treinamento.

Quanto? R\$1.500,00

Fonte: Elaborado pelo autor com base na coleta de dados, 2021.

No quadro 5, o levantamento das necessidades de treinamento pretende verificar as reais necessidades de cada colaborador, de que forma a empresa possa aperfeiçoálos e motivá-los, além de estipular até que ponto o problema existente é passível de solução por meio de treinamento.

Como resultado desta ação, se espera que o levantamento envolva a análise do contexto em conjunto com os colaboradores, mapeando problemas, prioridades e potencialidades que interferem no bom desempenho tanto do colaborador, como do setor logístico da empresa Gemar Supermercado.

\subsection{ESTABELECER UM CRONOGRAMA MENSAL DE INVESTIMENTO EM TREINAMENTO E DESENVOLVIMENTO DAS COMPETÊNCIAS}

O plano de treinamento é a ferramenta utilizada, neste cenário, para que a empresa consiga estruturar as capacitações e cursos essenciais a fim de que os colaboradores obtenham conhecimentos e desenvolvam habilidades. 
Redirecionar uma empresa, quanto seu modo de trabalho, é uma tarefa que necessita de ajustes, atenção constante e, sobretudo, de investimento, tanto de tempo quanto de dinheiro. Neste sentido, ressalta-se a importância de estabelecer um cronograma mensal de investimento em treinamentos bem elaborados que consiga obter lucros e não gerar mais problemas e custos.

Quadro 06: 5W2H - Estabelecer um cronograma mensal de investimento em treinamento e desenvolvimento das competências.

\section{DESCRIÇÃO}

O Que? Estabelecer um cronograma mensal de investimento em treinamento e desenvolvimento das competências.

Por quê? Devido à importância de manter o controle por meio da elaboração de cronogramas de investimento que presumirão os custos e ajudaram a poupar ao longo do tempo.

Como? Por meio de construção de cronograma

Quando? Permanentemente

Quem? Diretoria administrativa e demais líderes de setores de Rh e logística

Onde? Setor Logístico e de RH

Quanto? $\mathrm{R} \$ 2.500,00$

Fonte: Elaborado pelo autor com base na coleta de dados, 2021.

No quadro 06 , se estabelece a criação de um programa mensal de treinamento visando normatizar o exercício das atividades. O cronograma, também, é importante para os gestores da organização, que seguirão planejamentos permanentes de treinamento, dotando a organização de verba necessária para subsidiar estes treinamentos.

Dessa forma, tudo o que a empresa utilizar durante a elaboração do treinamento, visando garantir o alcance de metas, poderá ser presumido, orçado e poupado para sua aplicação no decorrer do ano. 
Espera-se que esta ação proporcione ganhos contínuos de conhecimentos assimilados ao longo do treinamento e, por meio deles, o trabalho seja aperfeiçoado, resultando no aumento da produtividade, melhora da comunicação e simetria entre os setores operantes da empresa.

\section{CONSIDERAÇÕES FINAIS}

A logística, como demonstrada no decorrer deste artigo, tem se destacado nos últimos anos. Por outro lado, a necessidade de infraestrutura e investimentos em treinamento para os colaboradores da área ainda é a grande realidade do mercado atual. Além disso, manter seu próprio valor competitivo, como também, de seus produtos, é outro desafio para empresas que buscam conceder serviços de qualidade que atendam a demanda e necessidades de seus clientes.

Para que uma empresa consiga se estabelecer e alcançar suas metas é preciso que seus processos produtivos estejam totalmente alinhados, apresentando o mínimo de perda, já que devido a tantas ações possíveis, os processos devem suportar as estratégias escolhidas pela empresa.

O objetivo deste artigo foi propor a implementação de políticas de treinamento baseando-se nas técnicas de gestão por competência a fim de estimular o desenvolvimento dos colaboradores que atuam no setor logístico do supermercado. Este foi atendido no sentido de que, através das propostas interventivas, estruturaram-se formatos de avaliação de necessidades de capacitação das equipes.

Retomando o problema de pesquisa: como as políticas de capacitações operativas podem proporcionar melhorias contínuas no processo logístico? Concluímos que a partir da introdução de um conjunto de capacitações relativas aos processos logísticos, como: técnicas logísticas, estoques de máximos e mínimos, gestão por categorias de estoque, custos de estoque, contagem cíclica, lote econômico de compras entre outras técnicas que proporcionam uma maior capacitação dos 
colaboradores do setor. Identifica-se o êxito na solução do problema, no sentido de construir um programa estruturado de capacitação, comparando competências existentes e competências necessárias, criando escalas de priorização.

Os objetivos específicos do estudo foram atendidos no sentido de abordar a relevância da gestão por competências e a criação de uma política estruturada de treinamento para a organização, possibilitando investigar quais são as competências prioritárias, bem como, as práticas e técnicas logísticas que precisam ser priorizadas no supermercado estudado.

Sendo assim, o presente artigo apresentou um conjunto de ações interventivas que permitiram à organização maximizar a eficiência das operações logísticas ancoradas na evolução da capacidade operativa dos colaboradores.

Com isso, além de aperfeiçoar os processos, o treinamento em logística permite que os colaboradores demonstrem sua capacidade em desenvolver soluções durante o dia a dia da empresa, facilitando e melhorando a rotina do setor, como: recebimento, envio, controle e reposição de mercadorias.

Por fim, ressalta-se que o investimento em treinamento ajuda a aprimorar os conhecimentos e habilidades dos colaboradores, estes por sua vez, tornam-se capazes de executar as tarefas seguindo o planejamento $\mathrm{e}$ atendendo as expectativas da empresa. Sendo assim, o setor logístico da empresa Gemar Supermercado obterá autonomia no gerenciamento de suas operações, principalmente as que envolvem a cadeia de suprimentos aumentando sua competitividade e atingindo a satisfação dos seus clientes.

Concluindo, entende-se que o presente artigo atingiu em sua plenitude a construção de propostas interventivas que solucionam os problemas identificados no diagnóstico organizacional, deixando soluções para empresa e um arcabouço fundamentado para futuras pesquisas sobre o tema. 


\section{REFERÊNCIAS BIBLIOGRÁFICAS}

ABRAS. Associação Brasileira de Supermercados. Economia e Pesquisa. São Paulo, 2017.

BALLOU, R. H. Logística Empresarial: transportes, administração de materiais e distribuição física. 27. ed. São Paulo: Atlas, 2012.

CARLOS, C. M. G; BAZON, S; OLIVEIRA, W de. A importância do treinamento e desenvolvimento nas empresas de pequeno porte na cidade de Araras. Revista Unar. UNAR (ISSN 1982-4920), Araras (SP), v. 6, n. 1, p. 15-30, 2012.

CASARIN, H. de C. S.; CASARIN, S. S. Pesquisa científica: da teoria à prática. Curitiba: Ed. Intersaberes, 2012;

CECCON, J. J. Os Conhecimentos, Habilidades e Atitudes necessários aos novos gestores em suas tomadas de decisão. Rio de Janeiro: 2013.

DUTRA, J. S. Gestão de pessoas: modelo, processos, tendências e perspectivas. 1. ed. 12. Reimpr. - São Paulo: Atlas, 2013.

FERNANDES, K. dos S. Logística: Fundamentos e processos. 1 ed. rev. Curitiba, PR: IESDE Brasil, 2012.

GOMES, D. et al. A Importância Do Gerenciamento De Estoque: Um Estudo De Caso Sobre Gargalos Encontrados Em Um Supermercado De Araguaína Tocantins.

JÚLIA, A. et al. A Relevância Dos Processos De Logística No Segmento De Distribuição De Bebidas Em Bebedouro - Sp. Revista Executive On-Line, Bebedouro SP, v. 3, n. 1, p. 43-58, 2018.

KNAPIK, J. Gestão de pessoas e talentos. 1. ed. - Curitiba: InterSaberes, 2012. 
LEAL, A. P. et al. Gestão de competências: competências individuais $\mathbf{x}$ competências organizacionais. Revista Científica Multidisciplinar Núcleo do Conhecimento. Ano 03, Ed. 08, Vol. 10, pp. 72-88, agosto de 2018.

KÖCHE, J. C. Fundamentos de Metodologia Científica: teoria da ciência e iniciação à pesquisa. 34º ed. Petrópolis, RJ: Vozes, 2011.

LISBOA, M. D. G. P. e GODOY, L. P. Aplicação do método 5W2H no processo produtivo do produto: a joia. Iberoamerican Journal of Industrial Engineering. 2012.

LIMA, M. A. M.; ROCHA, B. P. L. Avaliação de programas de gestão por competências: um estudo em organizações da Região Metropolitana de Fortaleza - CE. Organizações em Contexto, v. 8, n. 16, p. 167- 194, 2012.

LIBÓRIO, D.; TERRA, L. Metodologia científica. São Paulo: Rede Internacional de Universidade Laureate, 2015.

MASENSSINE, S. et al. Gestão de Processos de Estoque e Armazenagem Visando Redução de Custos. 2018.

NOGUEIRA, A. S. Logística empresarial: uma visão local com pensamento globalizado. São Paulo, Atlas, 2012.

NASCIMENTO, F. P. Metodologia da Pesquisa Científica - Teoria e Prática. Brasilia: Editora Thesaurus. , 2016.

MOURA, R. A. Check sua logística interna. São Paulo: Imam, 1998.

PRODANOV, C. C. (Org.). Metodologia do trabalho científico: métodos e técnicas da pesquisa e do trabalho acadêmico. 2. ed. Novo Hamburgo: Feevale, 2013. 
PEREIRA, C.; PASSOS, T. G. Treinamento e desenvolvimento de pessoas na organização. 2019.

RABAGLIO, M. O. Gestão por competências: ferramentas para atração e captação de talentos humanos. 2. ed. 3. Reimpr. - Rio de Janeiro: Qualitymark Editora, 2013.

SOUZA, A. A. et al. Logística hospitalar: Um estudo de caso diagnóstico das dificuldades na gestão logística do setor de engenharia clínica. Revista Eletrônica de Administração ISSN: 1679-9127 v. 12, n.1, ed. 22, jan-jun 2013.

SILVA, P.; MACHADO, G.; SILVA, L.; PROCÓPIO, P. Modelo de gestão logística na distribuição. Administração - Cadernos de Graduação. Ciências humanas e sociais, Recife, v. 2, n. 3, p. 89-99, Jun 2015.

TEOFILO, A. T. et al. Treinamento como ferramenta estratégica para o desenvolvimento corporativo. Simpósio de Excelência em Gestão e Tecnologia. 2013.

TRIGUEIRA, R. M. et al. Metodologia científica. 1르 ed. Londrina: Editora e Distribuidora Educacional S.A., 2014.

YIN, R. K. O Estudo de caso. Porto Alegre: Bookman, 2015.

ZANELLA, L. C. H. Metodologia de pesquisa. 2. ed. Florianópolis: Departamento de Ciências da Administração/ UFSC, 2013.

Enviado: Outubro, 2021.

Aprovado: Novembro, 2021. 